\title{
Les enquêtes dialectologiques de la Société d'Éthnolinguistique Bretonne : éléments de présentation du Questionnaire Grammatical 1500
}

\section{Adrien Desseigne et Pierre-Yves Kersulec}

\section{(2) OpenEdition}

\section{Journals}

Édition électronique

URL : https://journals.openedition.org//bl/1488

DOI : $10.4000 / \mathrm{lbl} .1488$

ISSN : 2727-9383

Éditeur

Université de Bretagne Occidentale - UBO

\section{Édition imprimée}

Date de publication : 1 mars 2014

Pagination : 87-109

ISBN : 979-10-92331-07-3

ISSN : 1270-2412

Référence électronique

Adrien Desseigne et Pierre-Yves Kersulec, «Les enquêtes dialectologiques de la Société

d'Éthnolinguistique Bretonne : éléments de présentation du Questionnaire Grammatical 1500 », La Bretagne Linguistique [En ligne], 18 | 2014, mis en ligne le 01 mai 2021, consulté le 22 mai 2021. URL http://journals.openedition.org/lbl/1488; DOI : https://doi.org/10.4000//bl.1488

Ce document a été généré automatiquement le 22 mai 2021.

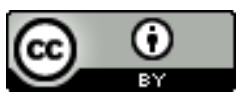

La Bretagne Linguistique est mise à disposition selon les termes de la Licence Creative Commons Attribution 4.0 International. 


\section{Les enquêtes dialectologiques de la Société d'Éthnolinguistique Bretonne : éléments de présentation du Questionnaire Grammatical 1500}

Adrien Desseigne et Pierre-Yves Kersulec

1 Texte disponible uniquement en format papier.

\section{AUTEURS}

\section{ADRIEN DESSEIGNE}

Titulaire de masters de Breton-Celtique, de Science du Langage et d'Ingénierie Linguistique, membre fondateur de la Société d'Ethnolinguistique Bretonne et adminsitrateur de la Banque Sonore des Dialectes Bretons.

PIERRE-YVES KERSULEC

Professeur certifié, titulaire d'un doctorat de celtique, membre fondateur de la Société d'Ethnolinguistique Bretonne. 